\title{
Correlation of MRI Brain Injury Findings with Neonatal Clinical Factors in Infants with Congenital Diaphragmatic Hernia
}

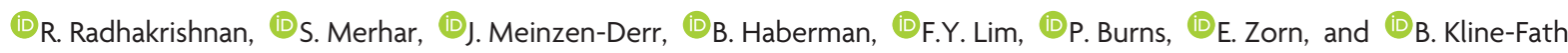

\begin{abstract}
BACKGROUND AND PURPOSE: Infants with congenital diaphragmatic hernia are reported to have evidence of brain MR imaging abnormalities. Our study aimed to identify perinatal clinical factors in infants with congenital diaphragmatic hernia that are associated with evidence of brain injury on MR imaging performed before hospital discharge.
\end{abstract}

MATERIALS AND METHODS: MRIs performed before hospital discharge in infants with congenital diaphragmatic hernia were scored for brain injury by 2 pediatric neuroradiologists. Perinatal variables and clinical variables from the neonatal intensive care unit stay were analyzed for potential associations with brain MR imaging findings.

RESULTS: Fifty-three infants with congenital diaphragmatic hernia (31 boys) were included. At least 1 abnormality was seen on MR imaging in 32 infants (60\%). The most common MR imaging findings were enlarged extra-axial spaces (36\%), intraventricular hemorrhage (23\%), ventriculomegaly (19\%), white matter injury (17\%), and cerebellar hemorrhage (17\%). The MR imaging brain injury score was associated with extracorporeal membrane oxygenation $(P=.0001)$, lack of oral feeding at discharge $(P=.012)$, use of inotropes $(P=.027)$, and gastrostomy tube placement before hospital discharge $(P=.024)$. The MR imaging brain injury score was also associated with a large diaphragmatic defect size $(P=.011)$.

CONCLUSIONS: Most infants with congenital diaphragmatic hernia have at least 1 abnormality identified on MR imaging of the brain performed before discharge. The main predictors of brain injury in this population are a requirement for extracorporeal membrane oxygenation, large diaphragmatic defect size, and lack of oral feeding at discharge.

ABBREVIATIONS: $\mathrm{CDH}=$ congenital diaphragmatic hernia; $\mathrm{ECMO}=$ extracorporeal membrane oxygenation

C ongenital diaphragmatic hernia $(\mathrm{CDH})$, with an incidence of case per 2000 live births, is an anomaly associated with substantial morbidity and mortality. ${ }^{1}$ Survivors of $\mathrm{CDH}$ are at risk for long-term respiratory, gastrointestinal, nutritional, hearing, and neurologic sequelae, requiring multidisciplinary support, especially during early childhood. ${ }^{1}$ Prenatal predictive factors for increased morbidity and mortality include prenatal imaging findings of liver herniation into the chest, lung to head ratio on prenatal sonography, or lung volumes on fetal MR imaging. ${ }^{2-4}$ The size of the diaphragmatic defect is another factor that likely plays a major role in morbidity and mortality in infants with

Received November 18, 2015; accepted after revision February 24, 2016.

From the Departments of Radiology (R.R., B.K.-F.), Biostatistics and Epidemiology (J.M.-D.), and Pediatrics (E.Z.); Perinatal Institute (S.M., B.H.), Division of Neonatology; and Fetal Care Center (F.Y.L., P.B.), Cincinnati Children's Hospital Medical Center, Cincinnati, Ohio.

Please address correspondence to Rupa Radhakrishnan, MD, Cincinnati Children's Hospital Medical Center, 3333 Burnet Ave, Cincinnati, OH 45229; e-mail: rupa.radhakrishnan@cchmc.org; @radrupa

http://dx.doi.org/10.3174/ajnr.A4787 congenital diaphragmatic hernia. ${ }^{5}$ However, the association of the defect size with evidence of injury on brain imaging has not been studied, to our knowledge.

Long-term neurodevelopmental and neurobehavioral disabilities are reported in up to $70 \%$ of infants with congenital diaphragmatic hernia. ${ }^{6-9}$ Both brain maturational delays and evidence of brain injury have been reported on imaging. ${ }^{8,9}$ There continues to be some controversy about the correlation of neuroimaging abnormalities in $\mathrm{CDH}$ with neurologic outcome. In a small cohort of patients with $\mathrm{CDH}$ with prenatal and postnatal imaging, Tracy et $\mathrm{al}^{9}$ identified an association between brain injury seen on postnatal CT/MR imaging in 4 infants and neurodevelopmental outcome at 1 year. There was no correlation between prenatal factors and neurodevelopmental outcome in this study. ${ }^{9}$ In another study by Danzer et al, ${ }^{10}$ postnatal brain MR imaging abnormalities were associated with lower cognitive scores, motor dysfunction, and language deficits.

The impact of extracorporeal membrane oxygenation (ECMO) on neonates with $\mathrm{CDH}$ requiring ECMO is of clinical relevance. Studies suggest that neonates with $\mathrm{CDH}$ who require 
ECMO have a greater incidence of adverse neurodevelopmental sequelae, though it unclear whether the severity of the illness leading up to ECMO (hypercapnia, hypotension, and so forth) or the ECMO itself should be implicated. ${ }^{6,11}$

Which clinical factors in the neonatal intensive care unit play a role in brain injury in infants with $\mathrm{CDH}$ is yet to be determined.

In this study, we have developed a brain injury score to determine whether brain injury seen on predischarge MRI in infants with $\mathrm{CDH}$ is associated with diaphragmatic defect size and postnatal clinical factors in the NICU.

\section{MATERIALS AND METHODS}

After institutional review board approval, we retrospectively identified infants with CDH born between February 2009 and March 2014. We included infants with CDH with MR imaging of the brain before discharge as described in the flow chart (Fig 1).

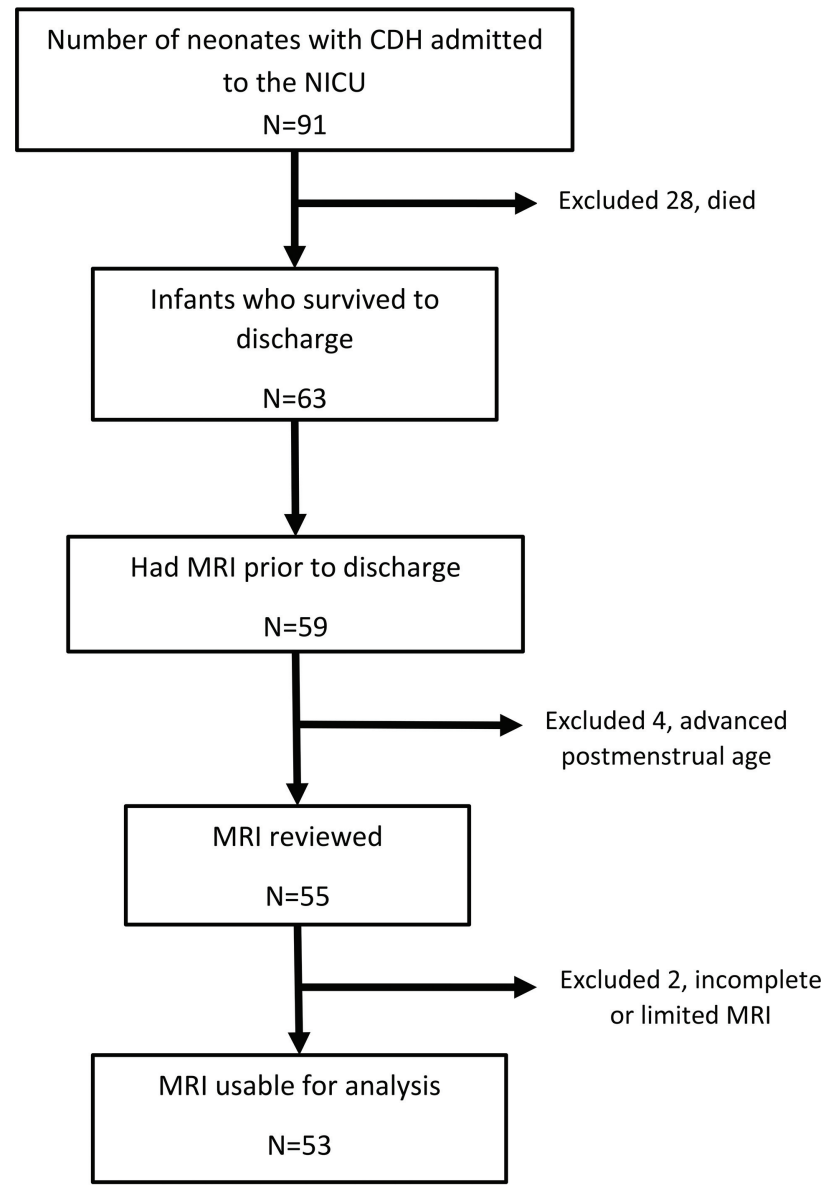

FIG 1. Flowchart of subject inclusion.
MR imaging was performed on these infants on $1.5 \mathrm{~T}$ and $3 \mathrm{~T}$, and with a small-bore extremity 1.5T MR imaging scanner that was adapted for neonatal imaging in the neonatal intensive care unit. ${ }^{12}$ MR imaging was performed without sedation after feeding and swaddling, except when excessive motion required light sedation. All studies included standard T1, T2, and susceptibility- and diffusion-weighted sequences.

The MR images were independently reviewed by 2 pediatric neuroradiologists who were blinded to the clinical variables except for postmenstrual age at the time of MR imaging. Conflicts were resolved by consensus. The brain was evaluated for evidence of injury and then was scored on the basis of a system modified from previous work by Danzer et al ${ }^{8,10}$ and Tracy et al. ${ }^{9}$ Table 1 lists the brain injury scoring guide. The total brain injury score was calculated in each infant. Examples of our scoring system are provided in Fig 2.

The medical charts were reviewed to identify perinatal clinical factors and courses in the neonatal intensive care unit. The clinical variables extracted from the electronic medical record included type of diaphragmatic defect, gestational age, birth weight, Apgar scores at 1 and 5 minutes, the presence of congenital heart disease, the need for ECMO, days on a ventilator, the presence of blood stream infection, the need for and type of inotropic support, the need for oxygen at 28 days of life, any oral feeding at discharge, and gastrostomy tube placement before hospital discharge. The size of the diaphragmatic defect identified at surgery was classified according to the Congenital Diaphragmatic Hernia Study Group classification from A to D, A being a small defect and D indicating diaphragmatic agenesis. ${ }^{5}$

Data were entered into REDCap (http://www.project-redcap. org/software.php), a secure on-line Web application. Statistical analysis was performed by using SAS software (Version 9.3; SAS Institute, Cary, North Carolina). Nonparametric tests and multivariable linear regression were performed by using clinical variables as potential predictors with the brain injury score as the continuous outcome.

\section{RESULTS}

There were 91 neonates with $\mathrm{CDH}$ admitted to the neonatal intensive care unit during the study; 28 died and 53 remained suitable for the study (Fig 1). Demographic details are provided in Table 2. Nine of the 53 neonates required ECMO during their treatment. In the 9 neonates who had ECMO, 2 had a type D defect and 7 had a type $\mathrm{C}$ defect.

MR imaging was performed at a mean corrected gestational age of 43.6 weeks (range, 37.0-64.6 weeks). Fifty of the 53 infants were imaged at $<48$ weeks' corrected gestational age. MR imaging

Table 1: Brain injury scoring system

\begin{tabular}{|c|c|c|c|c|c|}
\hline MRI Findings vs Score & 0 & 1 & 2 & 3 & 4 \\
\hline Ventriculomegaly & $<10 \mathrm{~mm}$ & $10-15 \mathrm{~mm}$ & $>15 \mathrm{~mm}$ & Obstructive & \\
\hline Extra-axial spaces & $<5 \mathrm{~mm}$ & $5-10 \mathrm{~mm}$ & $>10 \mathrm{~mm}$ & & \\
\hline Intraventricular hemorrhage & None & Grade 1 & Grade 2 & Grade 3 & Grade 4 \\
\hline $\begin{array}{l}\text { Parenchymal hemorrhage (not grade } 4 \\
\text { intraventricular hemorrhage) }\end{array}$ & Absent & Present & & & \\
\hline Cerebellar hemorrhage & None & $<3$ foci, $<5$-mm size & $>3$ foci or $>5-\mathrm{mm}$ size & & \\
\hline White matter injury & None & $<3$ foci, unilateral & $>3$ foci or bilateral & Multiregional & \\
\hline Cortical injury & None & Single & Multiple & Extensive & \\
\hline Basal ganglia injury & None & Single & Multiple & Extensive & \\
\hline
\end{tabular}




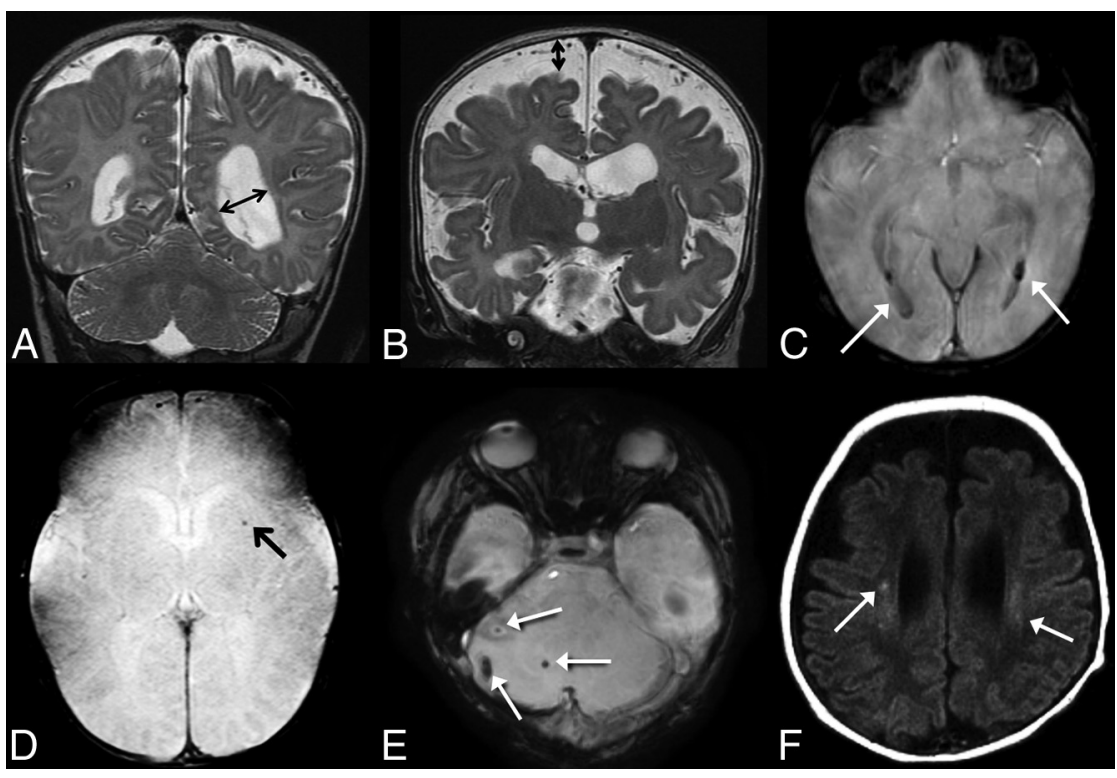

FIG 2. A, Coronal T2-weighted image demonstrates ventriculomegaly, scored as grade 2 on our scale; $B$, Coronal T2-weighted image demonstrates enlarged extra-axial spaces, scored as grade 2 on our scale. $C$, SWI shows evidence of grade 2 intraventricluar hemorrhage (arrows). D, SWI shows evidence of parenchymal hemorrhage, grade 1 on our scale (arrow). E, SWI shows foci of cerebellar hemorrhage, grade 2 on our scale (arrows). F, Axial T1 weighted images demonstrate foci of bilateral white matter injury, grade 2 on our scale (arrows).

Table 2: Demographic table

\begin{tabular}{lc}
\hline & $\begin{array}{c}\text { Total Infants in the Study } \\
(\mathbf{N}=53)\end{array}$ \\
\hline Male (\%) & $31(58 \%)$ \\
Gestational age at birth (wk) & $38(32.9-40.6)$ \\
Birth weight $(\mathrm{g})^{\mathrm{a}}$ & $2960(1430-4175)$ \\
Diaphragmatic defect & \\
A & $8(15 \%)$ \\
B & $16(30 \%)$ \\
C & $22(42 \%)$ \\
D & $7(13 \%)$ \\
Days on ventilator & a \\
Length of stay (day) & $27(8-88)$ \\
Age at repair (wk) & $60(15-210)$ \\
Required inotropic support (\%) & $9(1-54)$ \\
Required ECMO $(\%)$ & $35(66 \%)$ \\
Required $\mathrm{O}_{2}$ at 28 days of life $(\%)$ & $9(17 \%)$ \\
Any oral feeding at discharge $(\%)$ & $37(70 \%)$ \\
\hline
\end{tabular}

${ }^{a}$ Data are expressed as median (range).

findings were considered abnormal (injury score of $>0$ ) in 32/53 $(60 \%)$ infants. Enlarged extra-axial spaces were the most common abnormal finding on MR imaging, seen in 36\% of infants. Other abnormal findings on MR imaging included intraventricular hemorrhage in $23 \%$, ventriculomegaly in $19 \%$, white matter injury in $17 \%$, cerebellar hemorrhage in $17 \%$, parenchymal hemorrhage in $8 \%$, cortical injury in $4 \%$, and basal ganglia injury in $2 \%$ of infants. The distribution of brain injury scores in infants with $\mathrm{CDH}$ treated with ECMO and those without it is provided in Fig 3. Ventriculomegaly, enlarged extra-axial spaces, parenchymal hemorrhage, and white matter injury were seen significantly more often in neonates who required ECMO compared with those without it (Table 3).

With the Spearman correlation for continuous predictor variables, there was a weak but significant correlation of the brain injury score with the number of ventilator days (correlation coefficient, 0.34; $P=.0014$ ) and diaphragmatic defect severity (correlation coefficient, $0.30 ; P=$ .027). There was no correlation between total injury score and gestational age in weeks, birth weight, Apgar scores, or bloodstream infection.

Univariate analysis of median differences in the brain injury scores and clinical variables in the neonatal intensive care unit showed that the use of ECMO $(P=.0001)$, use of inotropes $(P=.027)$, gastronomy tube placement before discharge $(P=.012)$, and not taking any oral feeding at discharge $(P=.024)$ were significantly associated with higher MR imaging brain injury scores. When we grouped the diaphragmatic defects into small (A and $\mathrm{B}$ ) and large (C and D) defects, analysis with the Wilcoxon rank sum test showed that infants with type $\mathrm{C}$ or D diaphragmatic defects had significantly higher brain injury scores compared with infants with type A or B defects $(P=.011)$.

Table 4 lists the clinical predictors of brain injury. There was a significant association among the use of ECMO, the presence of C or $\mathrm{D}$ diaphragmatic defect, and evidence of brain injury. Infants who were taking any feeding by mouth (as opposed to being entirely tube-fed) at the time of discharge had a greater chance of having normal brain MR imaging findings.

To better understand the etiology of ventriculomegaly and enlarged extra-axial spaces, we plotted the head circumference measurements of infants imaged before 50 weeks' corrected gestational age on a standard Fenton head circumference chart (Fig 4). ${ }^{13}$ Head circumference was measured within 5 days of the brain MR imaging in all cases. Infants with moderate or severe enlargement of the extra-axial spaces had normal or enlarged head size.

\section{DISCUSSION}

Management of $\mathrm{CDH}$ is complex, with various strategies used to improve outcomes. In general, our clinical management strategy for infants with $\mathrm{CDH}$ includes gentle ventilation, aggressive management of pulmonary hypertension with pulmonary vasodilators such as nitric oxide and epoprostenol, and surgical repair when pulmonary hypertension is subsystemic or has stabilized. ECMO is reserved for extremely sick infants who do not respond to standard medical management. Despite improved therapies, the early course in infants with CDH continues to be an extremely vulnerable period with great morbidity. In this article, we report the associations between clinical variables in the critical neonatal intensive care unit period and MR imaging evidence of brain injury in infants with $\mathrm{CDH}$.

MR imaging has been used as a tool to identify evidence of perinatal brain injury in vulnerable populations and to predict 


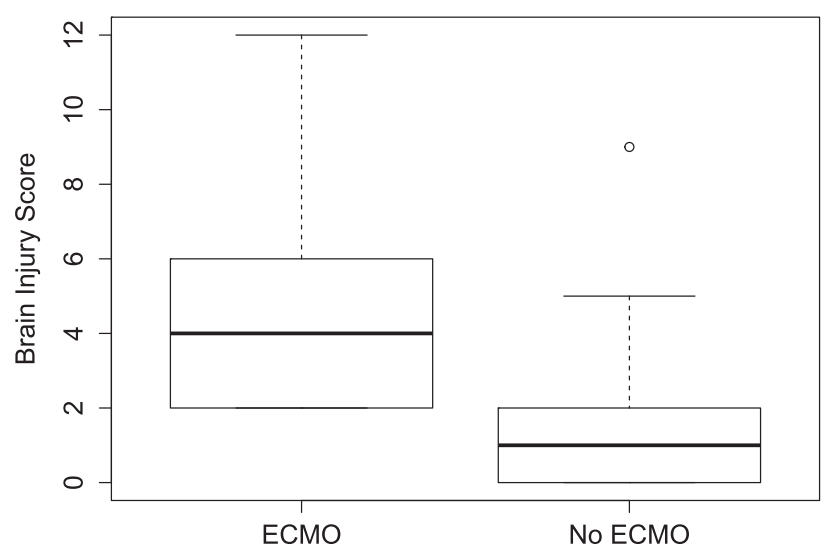

FIG 3. Boxplots of the distribution of the brain injury score in infants with $\mathrm{CDH}$ with $\mathrm{ECMO}$ and those without it. The central thick line in each box is the median score. The limits of the box indicate upper and lower quartiles. The whisker limits indicate the highest or lowest score, not considering outliers. There is 1 outlier with a higher brain injury score in the non-ECMO group with a score of $>1.5$ interquartile range above the upper quartile. This infant had a CDH defect $D$.

Table 3: Differences in the presence of brain injury between infants with and without ECMO

\begin{tabular}{lccc}
\hline & $\begin{array}{c}\text { ECMO } \\
(\boldsymbol{n}=\mathbf{9})\end{array}$ & $\begin{array}{c}\text { No ECMO } \\
(\boldsymbol{n}=\mathbf{4 4 )}\end{array}$ & $\boldsymbol{P ~ V a l u e ~}^{\mathbf{a}}$ \\
\hline Ventriculomegaly & $5(56 \%)$ & $8(18 \%)$ & .03 \\
Extra-axial spaces & $8(89 \%)$ & $11(25 \%)$ & $<.0001$ \\
Intraventricular hemorrhage & $4(44 \%)$ & $8(18 \%)$ & .18 \\
Parenchymal hemorrhage & $3(33 \%)$ & $1(2 \%)$ & .013 \\
Cerebellar hemorrhage & $3(33 \%)$ & $6(14 \%)$ & .17 \\
White matter injury & $4(44 \%)$ & $5(11 \%)$ & .035 \\
Cortical injury & $1(11 \%)$ & $1(2 \%)$ & .31 \\
Basal ganglia injury & $1(11 \%)$ & 0 & .17 \\
\hline
\end{tabular}

${ }^{a}$ Calculated using the Fisher exact test.

Table 4: Predictors of any brain injury on MRI

\begin{tabular}{|c|c|c|c|}
\hline & $\begin{array}{c}\text { Any Injury } \\
(n=32)\end{array}$ & $\begin{array}{l}\text { No Injury } \\
(n=21)\end{array}$ & $P$ Value \\
\hline Any oral feeding at discharge & $21(65.6 \%)$ & $19(90.5 \%)$ & .04 \\
\hline $\begin{array}{l}\text { Requirement for NG feeding } \\
\text { at discharge }\end{array}$ & $9(28.1 \%)$ & $10(47.6 \%)$ & .15 \\
\hline $\begin{array}{l}\text { G-tube placement before } \\
\text { discharge }\end{array}$ & $13(40.6 \%)$ & $4(19.1 \%)$ & .10 \\
\hline No inotropes & $9(28.1 \%)$ & $9(42.9 \%)$ & .27 \\
\hline Blood stream infection ${ }^{a}$ & $3(9.4 \%$ & 0 & $.27^{\mathrm{b}}$ \\
\hline Lung infection & $7(22.6 \%)$ & $2(9.5 \%)$ & $.28^{\mathrm{b}}$ \\
\hline Required $\mathrm{ECMO}^{\mathrm{a}}$ & $9(28.1 \%)$ & 0 & $.008^{\mathrm{b}}$ \\
\hline Diaphragmatic defect & & & .01 \\
\hline$A$ or $B$ & $10(31.3 \%)$ & $14(66.7 \%)$ & \\
\hline Cor D & $22(68.8 \%)$ & $7(33.3 \%)$ & \\
\hline
\end{tabular}

Note:-NG indicates nasogastic tube; G-tube, gastronomy tube.

${ }^{a}$ All infants had injury.

${ }^{\mathrm{b}}$ Fisher exact $P$ value.

neurodevelopmental outcome..$^{8,9,11,14-16}$ Consistent with previous small cohort studies, our results indicate that most infants with $\mathrm{CDH}$ have evidence of brain injury on MR imaging performed before discharge. Hunt et $\mathrm{al}^{17}$ identified white matter and deep gray matter injury in 8 of 10 patients with CDH. Tracy et $\mathrm{al}^{9}$ identified evidence of brain injury before discharge on 14 of 42 head ultrasounds, 7 of 8 brain MRIs, and 11 of 14 head CTs in infants with $\mathrm{CDH}$.

In our $\mathrm{CDH}$ population, enlarged extra-axial space was the most common abnormality, seen in $36 \%$ of the cases. This finding is similar to that in the cohort of Danzer et al, ${ }^{10}$ in which enlarged extra-axial spaces were present in $40 \%$ of the patients with $\mathrm{CDH}$. The enlarged extra-axial spaces were associated with lower cognitive scores in their study, and the presence of intracranial hemorrhage was associated with motor dysfunction. However, the effect of isolated enlarged extra-axial spaces on neurodevelopmental outcome, especially in neonates who have had ECMO, is somewhat controversial. ${ }^{18}$ Enlargement of the extra-axial spaces is a common finding in neonates with ECMO, particularly in venovenous ECMO. ${ }^{18-20}$ The obstruction of the internal jugular vein and/or the superior vena cava causes an elevation in intracranial venous pressure and poor resorption of CSF by the arachnoid villi. ${ }^{21}$ In neonates with $\mathrm{CDH}$, intrathoracic mass effect can cause relative obstruction of the central veins without ECMO. The large head circumferences in 2 of the 3 infants with ECMO with moderate-to-severe enlarged extra-axial spaces in our cohort support this hypothesis.

While our prevalence of parenchymal hemorrhage is similar to that in the study of Danzer et al, ${ }^{10}$ our cohort had a much higher incidence of intraventricular hemorrhage (23\% compared with $2 \%$ ). This may be due to use of susceptibility-weighted imaging in our population, which increases the sensitivity for the detection of blood products. In our study, infants on ECMO had a higher proportion of intraventricular and intraparenchymal hemorrhage compared with those without it. In 3 of these infants, minor intracranial hemorrhage was identified on screening head sonography during the course of ECMO, but this did not necessitate withdrawal of ECMO in these infants. We did not include small amounts of subdural or extra-axial hemorrhage in infants younger than 4 weeks of age as abnormal, given that this can be seen in healthy neonates following both vaginal and cesarean delivery. ${ }^{22}$ Although previous reports describe subdural hemorrhage in infants with $\mathrm{CDH}$, we did not see any abnormal subdural hemorrhage in our cohort.

Cerebellar hemorrhage was seen in $17 \%$ of our population and has not been previously described in infants with $\mathrm{CDH}$. Again, the use of SWI in our cohort may have increased the detection of this abnormality. The proposed etiology of cerebellar hemorrhage is impaired brain autoregulation, elevated venous pressure, and fetal distress. ${ }^{23}$ We did not find a significant difference in cerebellar hemorrhage between infants with and without ECMO.

Multiple intrauterine, perinatal, and surgical factors are described as associated with neonatal neurodevelopmental outcome, including the need for ECMO, the use of patch repair (a surrogate for large defect size), the presence of liver in the chest, the need for oxygen at 4 weeks of life, and hypotonicity. ${ }^{24,25}$ These factors would presumably also be associated with brain injury on imaging. Among the clinical variables assessed in our study, both large defect size and ECMO were predictors of the severity of brain injury identified on MR imaging. In our study, all the infants who needed ECMO had a large diaphragmatic defect; however, there was a substantial percentage $(38 \%)$ of infants with large defects who did not require ECMO. The need for supplemental oxygen at 4 weeks of life was not associated with brain injury on imaging in our study. As expected, all our patients who required ECMO had evidence of intracranial abnormality, com- 


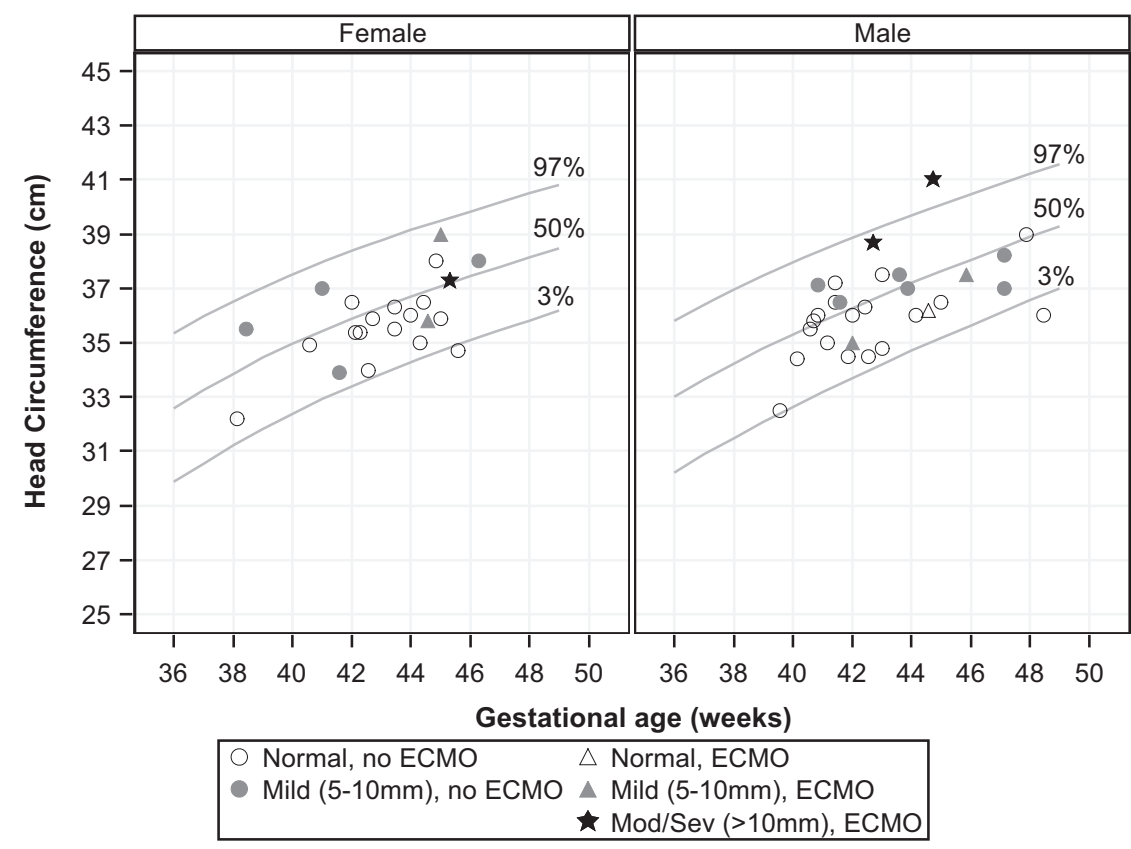

FIG 4. Enlarged extra-axial spaces versus head circumference, plotted on Fenton head circumference charts. ${ }^{13}$

pared with $52 \%$ of the group without ECMO. In a previous study from 1999, Ahmad et $\mathrm{al}^{11}$ showed that only $35 \%$ of patients with $\mathrm{CDH}$ and ECMO had evidence of CNS abnormality. This study used head sonography and CT to identify brain injury, and our numbers are likely higher due to the greater sensitivity of MR imaging in identifying subtle brain injury. In a study of infants with $\mathrm{CDH}$ from 1997, McGahren et $\mathrm{al}^{6}$ showed a greater incidence of intracranial findings on head sonography and poor neurologic outcome in infants with $\mathrm{CDH}$ requiring ECMO. Rollins et $\mathrm{al}^{26}$ performed a retrospective review of 50 neonates (24 with $\mathrm{CDH}$ ) who underwent brain MR imaging after neonatal ECMO. MR imaging findings were abnormal in $62 \%$ of the infants, and MR imaging was more sensitive than head sonography at detecting brain abnormalities. Similar to findings in our study, abnormal carotid flow, ventriculomegaly, and increased extra-axial spaces were common. They found that neuroimaging was, in fact, not correlated with neurodevelopmental outcomes in the 20 patients who had 12-month follow-up. However, they only classified neuroimaging findings as "normal" or "abnormal" and did not attempt to categorize the severity of imaging abnormalities, which could have potentially impacted their results.

Venoarterial ECMO, which is used at our center for infants with $\mathrm{CDH}$, requires cannulation of the right internal carotid artery. In addition to this vascular injury, systemic anticoagulation is required, greatly increasing the risk of cerebral hemorrhage. The initiation of ECMO launches a systemic inflammatory response, which also appears to affect the brain. ${ }^{27}$ Use of ECMO has been found to have an effect on neurodevelopmental outcome. Gross motor skills are delayed in many children who received ECMO as neonates compared with healthy controls, though severe disability is uncommon. ${ }^{28}$ Survivors of $\mathrm{CDH}$ who received ECMO appear to be more affected than those who required ECMO for other reasons, ${ }^{29}$ and the cause of poor outcome in this cohort is unclear. Cognitive development in ECMO survivors also appears to be overall within the normal range, but lower than that in healthy controls. $^{28}$ Decreased performance is seen on neuropsychological tasks such as verbal reasoning and spatial abilities, ${ }^{30}$ and children treated with ECMO are at risk for school difficulties despite normal overall intelligence. ${ }^{31,32}$ The increased brain injury seen in infants with $\mathrm{CDH}$ requiring ECMO in our study could provide a mechanism for some of these findings seen later in childhood.

Our study has several limitations. Because this is a retrospective study, we could not control for imaging timing, which might affect the identification of brain injury. Predischarge MR imaging examinations assessed in this study were performed when the infants were clinically stable after surgical correction and ECMO if used. The exact cause of brain injury in this $\mathrm{CDH}$ population, especially in those requiring ECMO, is difficult to postulate. Neonates who require ECMO are usually sicker than those who do not require ECMO, and they may have had a period of clinical instability with hypotension, hypercarbia, and impaired cerebral autoregulation before the initiation of ECMO. It is therefore difficult to determine whether ECMO itself or the illness requiring ECMO contributes more to brain injury. Even if they do not require ECMO, infants with $\mathrm{CDH}$ are often initially very sick, with episodes of hypoxia, hypercarbia, hypotension, and acidosis. Use of inotropes can be associated with altered cerebral perfusion leading to brain injury. ${ }^{33,34}$ Major surgery with anesthesia would also contribute to brain injury in these neonates. ${ }^{35,36}$

Only 53 of the 91 infants admitted to our neonatal intensive care unit during the study were included, mainly due to high mortality. Of the 28 infants who died, 21 had been on ECMO. Of the 63 survivors, 14 infants had ECMO and 9 were included in the study. The ECMO survivors that were included in our cohort may have represented the relatively less sick infants on ECMO who were clinically stable enough to be imaged. Because all our infants with ECMO had evidence of brain injury and the brain injury score was higher in infants with ECMO compared with those without it, it may be reasonably assumed that we imaged only the milder end of the spectrum and that infants with $\mathrm{CDH}$ needing ECMO would have a greater association with brain injury.

Imaging was performed on both $1.5 \mathrm{~T}$ and $3 \mathrm{~T}$ clinical scanners, which might affect the sensitivity of detection of brain abnormalities. We did not include sonography and CT reviews, because we believed that MR imaging was more sensitive in identifying brain injury. Neurodevelopmental tests on our group of infants with $\mathrm{CDH}$ are ongoing, and results are not included in this study. The clinical significance of the brain imaging abnormalities is therefore currently unknown. However, on the basis of available evi- 
dence of brain injury in infants with $\mathrm{CDH}$, all infants with $\mathrm{CDH}$ now undergo brain MR imaging before discharge.

\section{CONCLUSIONS}

In this study, we demonstrated an association between perinatal clinical factors and brain imaging abnormalities in infants with congenital diaphragmatic hernia. The strongest association with brain abnormality is the use of ECMO, with the most common abnormality being enlarged extra-axial spaces. The presence of a large diaphragmatic defect was an intrinsic factor associated with abnormal brain imaging findings. Infants who were fed orally at the time of discharge were more likely to have normal neuroimaging findings.

\section{ACKNOWLEDGMENTS}

We thank Meredith Tabangin, $\mathrm{PhD}$, from the Division of Biostatistics and Epidemiology, Cincinnati Children's Hospital Medical Center, for her help in plotting the extra-axial space score against infant head circumference (Fig 4).

Disclosures: Jareen Meinzen-Derr_UNRELATED: Grants/Grants Pending: March of Dimes. * Money paid to the institution.

\section{REFERENCES}

1. Robinson PD, Fitzgerald DA. Congenital diaphragmatic hernia. Paediatr Respir Rev 2007;8:323-34; quiz 334-35 CrossRef Medline

2. Hedrick HL, Danzer E, Merchant A, et al. Liver position and lungto-head ratio for prediction of extracorporeal membrane oxygenation and survival in isolated left congenital diaphragmatic hernia. Am J Obstet Gynecol 2007;197:422.e1-4 CrossRef Medline

3. Tsukimori K, Masumoto K, Morokuma S, et al. The lung-to-thorax transverse area ratio at term and near term correlates with survival in isolated congenital diaphragmatic hernia. J Ultrasound Med 2008; 27:707-13 Medline

4. Laudy JA, Van Gucht M, Van Dooren MF, et al. Congenital diaphragmatic hernia: an evaluation of the prognostic value of the lung-to-head ratio and other prenatal parameters. Prenat Diagn 2003;23:634-39 CrossRef Medline

5. Tsao K, Lally KP. The Congenital Diaphragmatic Hernia Study Group: a voluntary international registry. Semin Pediatr Surg 2008; 17:90-97 CrossRef Medline

6. McGahren ED, Mallik K, Rodgers BM. Neurological outcome is diminished in survivors of congenital diaphragmatic hernia requiring extracorporeal membrane oxygenation. J Pediatr Surg 1997;32: 1216-20 CrossRef Medline

7. Peetsold MG, Huisman J, Hofman VE, et al. Psychological outcome and quality of life in children born with congenital diaphragmatic hernia. Arch Dis Child 2009;94:834-40 CrossRef Medline

8. Danzer E, Gerdes M, D’Agostino JA, et al. Longitudinal neurodevelopmental and neuromotor outcome in congenital diaphragmatic hernia patients in the first 3 years of life. J Perinatol 2013;33:893-98 CrossRef Medline

9. Tracy S, Estroff J, Valim C, et al. Abnormal neuroimaging and neurodevelopmental findings in a cohort of antenatally diagnosed congenital diaphragmatic hernia survivors. J Pediatr Surg 2010;45: 958-65 CrossRef Medline

10. Danzer E, Zarnow D, Gerdes M, et al. Abnormal brain development and maturation on magnetic resonance imaging in survivors of severe congenital diaphragmatic hernia. J Pediatr Surg 2012;47: 453-61 CrossRef Medline

11. Ahmad A, Gangitano E, Odell RM, et al. Survival, intracranial lesions, and neurodevelopmental outcome in infants with congenital diaphragmatic hernia treated with extracorporeal membrane oxygenation. J Perinatol 1999;19(6 pt 1):436-40 CrossRef Medline
12. Tkach JA, Merhar SL, Kline-Fath BM, et al. MRI in the neonatal ICU: initial experience using a small-footprint 1.5 -T system. AJR Am J Roentgenol 2014;202:W95-W105 CrossRef Medline

13. Fenton TR, Kim JH. A systematic review and meta-analysis to revise the Fenton growth chart for preterm infants. BMC Pediatr 2013; 13:59 CrossRef Medline

14. Barkovich AJ, Hajnal BL, Vigneron D, et al. Prediction of neuromotor outcome in perinatal asphyxia: evaluation of MR scoring systems. AJNR Am J Neuroradiol 1998;19:143-49 Medline

15. Martinez-Biarge M, Bregant T, Wusthoff CJ, et al. White matter and cortical injury in hypoxic-ischemic encephalopathy: antecedent factors and 2-year outcome. J Pediatr 2012;161:799-807 CrossRef Medline

16. Inder TE, Warfield SK, Wang H, et al. Abnormal cerebral structure is present at term in premature infants. Pediatrics 2005;115:286-94 CrossRef Medline

17. Hunt RW, Kean MJ, Stewart MJ, et al. Patterns of cerebral injury in a series of infants with congenital diaphragmatic hernia utilizing magnetic resonance imaging. J Pediatr Surg 2004;39:31-36 CrossRef Medline

18. van Heijst AF, de Mol AC, Ijsselstijn H. ECMO in neonates: neuroimaging findings and outcome. Semin Perinatol 2014;38:104-13 CrossRef Medline

19. Bulas DI, Taylor GA, O’Donnell RM, et al. Intracranial abnormalities in infants treated with extracorporeal membrane oxygenation: update on sonographic and CT findings. AJNR Am J Neuroradiol 1996;17:287-94 Medline

20. Brunberg JA, Kewitz G, Schumacher RE. Venovenous extracorporeal membrane oxygenation: early CT alterations following use in management of severe respiratory failure in neonates. AJNR Am J Neuroradiol 1993;14:595-603 Medline

21. Stolar CJ, Reyes C. Extracorporeal membrane oxygenation causes significant changes in intracranial pressure and carotid artery blood flow in newborn lambs. J Pediatr Sug 1988;23:1163-68 CrossRef Medline

22. Rooks VJ, Eaton JP, Ruess L, et al. Prevalence and evolution of intracranial hemorrhage in asymptomatic term infants. AJNR Am J Neuroradiol 2008;29:1082-89 CrossRef Medline

23. Limperopoulos C, Benson CB, Bassan H, et al. Cerebellar hemorrhage in the preterm infant: ultrasonographic findings and risk factors. Pediatrics 2005;116:717-24 CrossRef Medline

24. Danzer E, Gerdes M, Bernbaum J, et al. Neurodevelopmental outcome of infants with congenital diaphragmatic hernia prospectively enrolled in an interdisciplinary follow-up program. J Pediatr Surg 2010;45:1759-66 CrossRef Medline

25. Danzer E, Hedrick HL. Neurodevelopmental and neurofunctional outcomes in children with congenital diaphragmatic hernia. Early Hum Dev 2011;87:625-32 CrossRef Medline

26. Rollins MD, Yoder BA, Moore KR, et al. Utility of neuroradiographic imaging in predicting outcomes after neonatal extracorporeal membrane oxygenation. J Pediatr Surg 2012;47:76-80 CrossRef Medline

27. Chen Q, Yu W, Shi J, et al. The effect of extracorporeal membrane oxygenation therapy on systemic oxidative stress injury in a porcine model. Artif Organs 2014;38:426-31 CrossRef Medline

28. Glass $\mathrm{P}, \mathrm{W}$ agner AE, Papero $\mathrm{PH}$, et al. Neurodevelopmental status at age five years of neonates treated with extracorporeal membrane oxygenation. J Pediatr 1995;127:447-57 CrossRef Medline

29. Bernbaum, J, Schwartz IP, Gerdes M, et al. Survivors of extracorporeal membrane oxygenation at 1 year of age: the relationship of primary diagnosis with health and neurodevelopmental sequelae. Pediatrics 1995;96(5 pt 1):907-13 Medline

30. Bennett CC, Johnson A, Field DJ, al; UK Collaborative ECMO Trial Group. UK collaborative randomised trial of neonatal extracorporeal membrane oxygenation: follow-up to age 4 years. Lancet 2001; 357:1094-96 CrossRef Medline

31. Madderom MJ, Reuser JJ, Utens EM, et al. Neurodevelopmental, educational and behavioral outcome at 8 years after neonatal 
ECMO: a nationwide multicenter study. Intensive Care Med 2013;39: 1584-93 CrossRef Medline

32. Rais-Bahrami K, Wagner AE, Coffman C, et al. Neurodevelopmental outcome in ECMO vs near-miss ECMO patients at 5 years of age. Clin Pediatr (Phila) 2000;39:145-52 CrossRef Medline

33. Kidokoro H, Anderson PJ, Doyle LW, et al. Brain injury and altered brain growth in preterm infants: predictors and prognosis. Pediatrics 2014;134:e444-53 CrossRef Medline

34. Hahn GH, Hyttel-Sorensen S, Petersen SM, et al. Cerebral effects of commonly used vasopressor-inotropes: a study in newborn piglets. PLoS One 2013;8:e63069 CrossRef Medline

35. Filan PM, Hunt RW, Anderson PJ, et al. Neurologic outcomes in very preterm infants undergoing surgery. J Pediatr 2012;160:409-14 CrossRef

36. Walker K, Badawi N, Halliday R, et al. Early developmental outcomes following major noncardiac and cardiac surgery in term infants: a population-based study. J Pediatr 2012;161:748-752.e1 CrossRef Medline 